\title{
DIRETRIZES CURRICULARES NACIONAIS PARA O ENSINO FUNDAMENTAL DE 9 ANOS E O PLANO NACIONAL DE EDUCAÇÃO: ABRINDO A DISCUSSÃO
}

\author{
LuCíOla Licínio SANTOS*
}

\begin{abstract}
RESUMO: O objetivo desse artigo é levantar alguns pontos que caracterizaram o processo de elaboração do Parecer e do Projeto de Resolução das Diretrizes Curriculares Nacionais para o Ensino Fundamental de 9 (nove) anos (Parecer CNE/CEB n. 11/2010), encaminhados ao ministro da Educação. A finalidade é contribuir com futuros estudos que busquem discutir uma política pública, considerando seu processo de elaboração, os atores envolvidos, as disputas e os interesses em jogo. Ao lado disso, procuro estabelecer um diálogo dessa proposta de Diretrizes com o Plano Nacional de Educação (PNE) elaborado pela Conferência Nacional de Educação (CONAE). A comparação entre esses dois textos vai mostrar que, mesmo se tratando de documentos de natureza e fins distintos, há uma grande convergência de ideias entre eles, fruto do percurso de sua construção e da presença de atores participantes dos dois processos.
\end{abstract}

Palavras-chave: Políticas educacionais. Diretrizes curriculares. Currículo. Plano Nacional de Educação. Ensino fundamental.

\section{NATIONAL CURRICULUM GUIDELINES FOR ELEMENTARY SCHOOL AND NATIONAL PLAN FOR EDUCATION: OPENING THE DISCUSSION}

ABSTRACT: This paper raises some points that have characterized the construction process of the Preliminary Part and of the Bill on the National Curriculum Guidelines for 9 (nine) years Elementary Education (Parecer CNE/CEB n. 11/2010) sent to be ratified by the

Doutora em Educação e professora do Departamento de Administração Escolar da Faculdade de Educação da Universidade Federal de Minas Gerais (UfMG). E-mail: luciolaufmg@yahoo.com.br 
Diretrizes Curriculares Nacionais para o ensino fundamental de 9 anos...

Minister of Education. The purpose is to contribute to future studies that seek to discuss public policies considering their development process, the actors involved, the disputes and the interests at stake. Besides, it establishes a dialogue with the Guidelines for the National Plan for Education prepared by the National Conference on Education (CONAE). Comparing both texts shows that even when dealing with documents of different nature and purposes, there is a considerable convergence of ideas, because of their similar construction process and similar participation process - same actors in both processes.

Key words: Educational policies. Curriculum guidelines. Curriculum studies. National Plan for Education. Elementary education.

\section{Introdução}

E sse artigo se constitui em uma análise preliminar das Diretrizes Nacionais para o Ensino Fundamental. Digo preliminar em dois sentidos. No primeiro, porque a Resolução que define essas Diretrizes ainda está em fase de homologação e, por isso, vou me basear na versão que foi encaminhada ao ministro da Educação e que poderá sofrer modificações. Em outro sentido, a análise é preliminar porque, sendo a primeira, não conta com o auxílio de outros trabalhos sobre a temática, que trariam diferentes olhares e mesmo diferentes perspectivas e que permitiriam um aprofundamento das questóes abordadas e o levantamento de novos problemas.

O objetivo do artigo é levantar alguns pontos que caracterizaram o processo de elaboração do Parecer e o Projeto de Resolução das Diretrizes Curriculares Nacionais para o Ensino Fundamental de 9 (nove) anos (Parecer CNE/CEB n. 11/2010), encaminhados ao ministro da Educação. Nesse sentido, a finalidade é contribuir com futuros estudos que busquem discutir uma política pública, considerando seu processo de elaboração, os atores envolvidos, as disputas e os interesses em jogo. Ao lado disso, procuro estabelecer um diálogo dessa proposta de Diretrizes com o Plano Nacional de Educação (PNE) elaborado pela Conferência Nacional de Educação (CONAE). Esse diálogo se torna imprescindível, uma vez que o PNE estabelece uma política de Estado que, através de ações integradas, baseadas em orientações comuns, venha a superar o atraso educacional, por meio da "garantia de um padrão de 
qualidade nas instituições públicas e privadas em todo o País” (CONAE, 2010, p. 26). A avaliação das políticas públicas, aspecto enfatizado pela Conferência, exige, por conseguinte, um exame constante de suas articulações com o PNE para que, de fato, seja construído e consolidado o Sistema Nacional de Educação.

Julgo, a partir de trabalhos de autores como Dale (1989), Goodson (1995), Ball (1992, 1994, 2007 e 2009), Ozga (2000), Apple (2001), Whitty (2002), e Torres (2004), entre outros, que para estudar, discutir ou analisar uma política educacional são necessários alguns cuidados que passo a enumerar. Em primeiro lugar, é preciso considerar os contextos em que essas políticas estão sendo produzidas: o local e o internacional. Em relação a este último, considero que, além das orientações difundidas pelos organismos internacionais e dos diferentes acordos internacionais em que o Brasil é signatário, há também uma influência das análises dos trabalhos acadêmicos de diferentes países sobre o pensamento e aspirações de grupos locais.

Em segundo lugar, é importante observar que os textos políticos são produzidos por meio de confrontos, lutas, acordos e consensos que o texto final busca quase sempre apagar, mas que ficam registrados, às vezes, de forma mais clara e, outras vezes, de maneira bem sutil, cabendo ao leitor ou ao analista buscar descobri-los.

Em terceiro lugar, julgo que é necessário entender que os documentos oficiais representam um conjunto de propostas que indicam as ideias hegemônicas em um determinado período e em um determinado contexto. Isso indica que há vozes silenciadas nos discursos políticos, assim como é possível também identificar que as vozes presentes neste discurso ocupam lugares diferentes. Há grupos que falam mais alto que outros, indicando a presença de hierarquias de poder no cenário social. Decorre daí o fato de que esse discurso será fatalmente contestado pelos que não tiveram espaço algum para se manifestar, como também por aqueles cujo espaço foi reduzido pela valorização de outras ideias diferentes ou contrárias às suas.

Em quarto lugar, o discurso político do Estado, como discurso oficial, representa também o ideário de uma época, podendo não se realizar ou se realizar apenas parcialmente, pelas dificuldades práticas para sua efetivação, tanto em decorrência dos motivos ora apresentados, como pela falta de estruturas materiais e humanas que o sustentem. 
Diretrizes Curriculares Nacionais para o ensino fundamental de 9 anos...

Além disso, o discurso oficial é interpretado, a partir da cultura local que o transforma ou o recontextualiza, de acordo com as experiências de seus agentes e das condiçôes presentes naquele espaço.

Em quinto lugar, há que se levar em conta as políticas em outras áreas que se relacionam com a educação. Assim, não há possibilidade de grandes realizações no campo educacional se não tivermos políticas mais democráticas no campo da saúde, do emprego, da habitação e de salários. Sem uma melhor distribuição de renda não é possível uma melhora significativa do desempenho escolar.

Os aspectos levantados antes se referem a questóes que devem ser consideradas na análise das políticas públicas e que fazem parte de um quadro teórico mais amplo, construído com a contribuição da literatura internacional, sendo, desse modo, ferramentas de análise. No entanto, é preciso ir mais adiante, no sentido de considerar a produção brasileira na área. Sem dúvida, são inegáveis os avanços nesse campo, pois os trabalhos ganham cada vez mais consistência, tanto pelos dados empíricos que os sustentam como pelo refinamento das análises. Entretanto, ainda se percebe na área alguns problemas que precisam ser enfrentados e que passo a discutir.

Pode-se dizer que estamos vivenciando um período em que a educação ganha um destaque nunca alcançado, o que pode ser comprovado por essa campanha eleitoral, pelo espaço que a educação ocupa na propaganda e programa dos candidatos de todos os partidos. É claro que esse aumento do interesse pela educação advém, sobretudo, da divulgação dos baixos resultados do desempenho dos alunos da educação bási$\mathrm{ca}^{1}{ }^{1}$ no período em que o Brasil sofre as consequências da falta de mão de obra qualificada, levando o país a importá-la. Nessa perspectiva, o aumento do interesse pela educação pode ser entendido como resultado do aumento de demandas relativas à qualificação da mão de obra e também da necessidade de ampliar a capacidade do país atrair investimentos, a partir da melhoria de seus índices educacionais. Se, internamente, há um interesse renovado e ampliado em relação à educação, o que pode ser observado pelo movimento "todos pela educação", ${ }^{2}$ a literatura no campo das políticas educacionais tem mostrado que o mesmo tem ocorrido em vários países da Europa, bem como nos Estados Unidos, Austrália, Nova Zelândia e Canadá, entre outros, em que uma série de reformas foi e está sendo introduzida, com vistas a maior eficiência dos sistemas educacionais. 
A literatura educacional também tem mostrado que essas mudanças quase sempre se orientam por critérios estritamente econômicos, decorrentes de uma visão mercantil e mercadológica da educação, que passa a ser submetida a uma lógica empresarial nas suas formas de organização e funcionamento.

Uma análise cuidadosa de produção acadêmica no campo das políticas educacionais irá mostrar a grande influência em suas análises da produção crítica realizada pelos acadêmicos estrangeiros, sobretudo, por acadêmicos dos países citados que se contrapõem fortemente às políticas levadas a cabo em seus países. É claro que o acesso às produçôes estrangeiras, possibilitado pela disponibilização de textos em sites e portais da internet e pela facilidade de compra on-line, contribui para o desenvolvimento de nossos estudos e pesquisas, pois a circulação de ideias fertiliza nosso campo acadêmico e é elemento fundamental para seu desenvolvimento. No entanto, há sempre o perigo de que ocorram transposições apressadas, interpretações equivocadas e tentativas de se encaixar à realidade, de forma forçada, as teorias atraentes e bem articuladas formuladas em terras do além-mar. Esse é um primeiro alerta, uma vez que problemas dessa natureza não decorrem da nossa falta de imaginação política, mas das circunstâncias a que está submetida nossa produção, uma vez que as exigências de produtividade podem se constituir em fatores inibidores da criatividade.

Além do problema apontado anteriormente, observa-se que a história da produção acadêmica no campo educacional deixou algumas marcas que perduram até hoje em algumas análises. Os trabalhos em forma de livros e artigos, sobretudo os produzidos na primeira metade dos anos de 1980, mostram sinais da luta contra a ditadura militar e, por isso, entende-se seu caráter muitas vezes militante e apaixonado e justificamse até mesmo seus vieses, na crítica contundente feita a tudo aquilo que partia do governo. Em decorrência disso, é necessário estarmos atentos ao contexto político mais amplo, conscientes de que nosso objetivo é uma crítica que possibilite uma melhor compreensão da realidade, o que cria condiçôes para o enfretamento dos problemas detectados.

Hoje, quando grande parte das políticas educacionais é elaborada com a participação direta de acadêmicos (na figura do consultor ou assessor) e/ou por meio de representantes de órgãos e associações do campo acadêmico ou a ele relacionados, como a Associação Nacional de 
Pós-graduação e Pesquisa em educação (ANPEd), Associação Nacional pela Formação dos Profissionais da Educação (ANFOpE) e Associação Nacional de Política e Administração da Educação (ANPAE), entre outras, ainda se observa sinais do mesmo de orientação, ou seja, alguns trabalhos acadêmicos ainda trazem esta marca de oposição a qualquer discurso e/ou ação governamental. $\mathrm{O}$ que quero enfatizar é que não estamos mais em uma posição de "eles e nós", porque há hoje uma grande interação dos gestores do Estado no campo educacional com os acadêmicos, suas associações e sindicatos, bem como com as lideranças dos movimentos sociais. Com isso, não estou dizendo que tudo que é produzido nessas circunstâncias vai ao encontro dos interesses sociais mais amplos, voltados para a construção de uma sociedade mais justa. Entendo que não podemos deixar de desconfiar dos interesses econômicos escusos ou da defesa de interesses privados que podem estar incrustados nos discursos das políticas públicas atuais. Afinal, os próprios acadêmicos idealizadores e defensores de muitas decisões políticas não estão em posição privilegiada, isentos da influência do ideário economicista e do controle social que permeia o campo e, muito menos ainda, da influência de valores da sociedade de consumo, como a competição, o individualismo, o narcisismo, por exemplo. Não podemos deixar de considerar que muitas propostas e iniciativas políticas que trazem a marca do catecismo do "novo gerencialismo"3 foram e estão sendo divulgadas por alguns artigos, palestras e outras manifestaçôes advindas do campo acadêmico. Acrescenta-se a isso que é também necessário considerar que, face às múltiplas interpelações a que somos expostos, estamos sujeitos a abraçarmos conceitos ou ideias que têm origem em produções de orientação distinta daquelas que professamos. Nesse cenário, não só as políticas públicas apresentam aspectos contraditórios, como também nossos próprios discursos, realidade a que este texto não consegue escapar.

\section{A trajetória das Diretrizes: breve relato}

Segundo o histórico que consta no Parecer CNE/CEB n. 11/2010, o próprio ministro da Educação solicitou ao Conselho Nacional de Educação (CNE) a elaboração de diretrizes para as etapas da educação básica, diante da necessidade de atualização e de revisão das resoluçôes em vigor e da incorporação, nessa nova legislação, das normas legais aprovadas na presente década. A Secretaria de Educação Básica do Ministério de Educação 
(SEB/MEC) ficou incumbida de elaborar um documento inicial. Este foi discutido em três audiências públicas (Salvador, 12/3/2010; Brasília, 5/4/ 2010; São Paulo, 16/4/2010), das quais participaram representantes e membros do Conselho Nacional de Secretários da Educação (CONSED), da União Nacional dos dirigentes Municipais de Educação (UNDimE), do Fórum Nacional dos Conselhos Estaduais de Educação (FNCEE), da Associação Nacional pela Formação dos Profissionais da Educação (ANFOPE), da Associação Nacional de Política e Administração da Educação (ANPAE), da Associação Nacional de Pós-Graduação e Pesquisa em Educação (ANPEd), da Confederação Nacional de Trabalhadores em Educação (CNTE), do Fórum de Diretores de Centros, Faculdades e Departamentos de Educação das Universidades Públicas Brasileiras (FOrUmdr), da Sociedade Brasileira pelo Progresso da Ciência (SBPC), da Comissão de Educação e Cultura da Câmara dos Deputados, da Comissão de Educação do Senado Federal, de coordenadores estaduais do ensino fundamental, de representantes de movimentos socais e das escolas privadas, entre outros.

A partir das sugestôes dos diferentes grupos e de contribuições pessoais, o documento inicial passou por diversas modificaçōes. Em sua versão final, depois do relato da forma como o trabalho foi realizado (histórico), o documento introduz um segundo item ou tópico, sob o título "Fundamentos", que apresenta os seguintes subtítulos: "O direito à educação como fundamento maior destas diretrizes", "A oferta de uma educação com qualidade social" e "Princípios norteadores". O terceiro tópico, intitulado "Trajetória do ensino fundamental obrigatório no país", apresenta um subtítulo sobre a matrícula no ensino fundamental de nove anos e sua carga horária. O quarto item discute a população escolar, dando ênfase às múltiplas infâncias e adolescências, e a ampliação dos objetivos da escola em face desse seu alunado. O quinto tópico aborda o currículo, destacando a complementaridade entre a base nacional comum e a parte diversificada, e também discute a apropriação da cultura pelos alunos. O sexto item trata de diversos temas: do projeto políticopedagógico, abordando a gestão democrática e participativa como garantia do direito à educação, da relevância dos conteúdos, da integração e das abordagens do currículo, das articulações do ensino fundamental como elemento facilitador da continuidade da trajetória escolar dos alunos, da entrada da criança de 6 anos no ensino fundamental e da avaliação. O sétimo item trata da educação em tempo integral, enquanto o oitavo é intitulado "Educação do campo: educação escolar indígena e 
Diretrizes Curriculares Nacionais para o ensino fundamental de 9 anos...

educação escolar quilombola”. Por último, os itens 9, 10 e 11 abordam, respectivamente, a educação especial, a educação de jovens e adultos e a necessidade de empenho solidário das redes e sistemas de ensino com a implantação das Diretrizes. Finalmente, o documento apresenta o Projeto de Resolução, que contém 50 artigos separados pelos mesmos temas antes assinalados, sendo que alguns desaparecem pelo seu caráter diagnóstico e outros se desdobram, sendo que alguns subtítulos passaram a ser títulos.

Destacam-se nessas Diretrizes o grande número de artigos, sem contar os vários parágrafos e incisos que muitos deles apresentam. Essa extensão revela claramente a preocupação em abarcar diferentes aspetos da educação escolar e representa uma tentativa de contemplar os interesses de diferentes grupos. Assim, há artigos que se referem às aspirações da sociedade, de um modo geral, outros que se voltam para demandas mais estreitamente relacionadas aos interesses dos movimentos sociais, das associações profissionais dos gestores do sistema, dos educadores críticos que se voltam com mais entusiasmo e interesse para os aspectos políticos da educação e também os que dão maior ênfase aos seus aspectos pedagógicos.

As Diretrizes anteriores (Parecer CNE/CEB n. 04/98) se distinguem, na forma e no conteúdo, da proposta atual. Para dar apenas um exemplo, enquanto a atual proposta tem 50 artigos, a anterior tem apenas sete. Mesmo que essa diferença representasse apenas um desejo de melhor explicitar princípios e orientaçôes semelhantes às anteriores, só esse fato já corresponde a um entendimento diferenciado da realidade educacional brasileira. O próprio parecer do CNE sobre as Diretrizes homologadas em 1998 é estruturado com outro formato. Nele, depois de apresentar a "introdução" e os "antecedentes", em uma terceira parte são apresentadas as Diretrizes, sendo cada um de seus artigos seguidos de uma justificativa ou de uma argumentação a respeito da importância da questão abordada. Por último, está o Projeto de Resolução apresentado em duas páginas, enquanto o atual, que aguarda homologação, tem cerca de treze páginas.

\section{As Diretrizes Curriculares Nacionais para o Ensino Fundamental e o Plano Nacional de Educação: principais convergências}

Nessa parte do trabalho, busco identificar alguns pontos de convergência entre o Plano Nacional de Educação (PNE) e as Diretrizes Nacionais para o Ensino Fundamental, procurando mostrar que propostas semelhantes podem ser feitas com base em orientaçóes distintas, do ponto 
de vista teórico e epistemológico e, além disso, as propostas apresentadas no processo de sua implementação podem ser transformadas, passando a assumir um significado distinto daquele em que se originaram.

Vou me valer de polarizações para explicar posições que circulam no campo. Estas polarizações têm fim didático, pois não existem na realidade, assumindo aqui o mesmo papel que o dos "tipos ideais". Este artigo deixa de apontar aspectos em que essas políticas apresentam divergências, pois a leitura dos documentos mostra não ser esse um caminho promissor. $\mathrm{O}$ aumento vertiginoso das possibilidades de comunicação tem possibilitado ampla divulgação e circulação de ideias, o que tem provocado uma grande convergência quando se trata de identificar as temáticas trabalhadas em um campo.

Frente a isso, considero que o mais consequente é examinar em que perspectivas essas temáticas são abordadas. Nesse sentido, apresento apenas dois extremos de significados que, do ponto de vista ideal, corresponderiam a duas agendas diferentes. Uma delas se identifica com o que chamo de proposta dos educadores críticos, que corresponderia às posições daqueles que trabalham com a educação como emancipação, estando esta voltada para a construção de uma sociedade mais justa, combatendo, portanto, todos os tipos de assimetrias sociais (tipo ideal). A outra agenda se afina com a tradição eficientista da educação, que privilegia critérios econômicos em suas decisões, em detrimento, em geral, de critérios voltados para aspectos formativos (tipo ideal). Esta última posição é coerente com princípios postos por organismos internacionais, como o Banco Mundial ou a Organisation for Economic Co-operation and Development (OECD), cuja preocupação maior é aumentar a eficiência dos sistemas educacionais, partindo de critérios econômicos e da introdução da cultura empresarial, baseada em princípios derivados do funcionamento do mercado e da organização do trabalho e centrada na avaliação do desempenho, medido em termos do alcance de metas preestabelecidas. Ao lado disso, defendem a ideia da aliança entre o setor público, o setor privado e o terceiro setor para o financiamento e desenvolvimento de projetos educacionais. $\mathrm{O}$ objetivo central posto para a educação é de que esta possa atender às demandas oriundas do mercado de trabalho, aumentando a competitividade da mão de obra do país.

Os educadores críticos também estão preocupados com os aspectos econômicos da educação, mas entendem que a questão primordial da educação e ponto a ser considerado em qualquer tomada de decisão 
Diretrizes Curriculares Nacionais para o ensino fundamental de 9 anos...

diz respeito à sua dimensão formativa. Para esse grupo, o objetivo central da educação é preparar as pessoas para uma atuação cidadã, o que significa alcançar, por meio da educação, uma formação que contemple duas dimensôes: o desenvolvimento das capacidades de resolução de problemas individuais, incluindo aqueles relacionados com a sobrevivência, e das capacidades que possibilitem a atuação das pessoas em diferentes esferas da vida pública.

Ao definir esses dois extremos, estou apenas levantando qual é a extensão do terreno, em termos de possibilidades, no qual uma política pode se configurar. Todavia, entendo que cada um desses extremos também é marcado por diferenças, pois "sociedade justa" e "emancipação" significam coisas bem diferentes para os diversos grupos sociais. Da mesma forma, muitos são os caminhos da eficiência e da eficácia no trato das coisas públicas. Como já afirmei, é óbvio que estas posições não se encontram de forma clara e nítida em discursos ou práticas, pois, na verdade, o que se percebe no campo educacional é uma mescla dessas ideias. Nessa mesma direção, Ball (2004) afirma que a criação de políticas nacionais é um processo que mescla influências, pois, além de adotar ideias na moda, sofre a influência das pesquisas, envolvendo também melhoria de ideias já utilizadas e de tudo aquilo que parece que irá funcionar. Considero que o argumento do autor sobre a criação de políticas é também pertinente para as análises que são feitas sobre essas políticas no campo educacional. Segundo Ball (op. cit., p. 102):

A criação de políticas nacionais é, inevitavelmente, um processo de "bricolagem"; um constante processo de empréstimos e cópia de fragmentos e partes de ideias de outros contextos, de uso e melhoria das abordagens locais já tentadas e testadas, de teorias canibalizadoras, de investigação, de adoção de tendências e modas e, por vezes, de investimento em tudo aquilo que possa vir a funcionar.

Em decorrência do exposto, julgo que a primeira coisa em uma análise política é identificar em que campo a política se situa, dentro dessas duas vertentes: está ligada ao projeto dos educadores críticos ou à corrente economicista? Esse é o trabalho preliminar, porque imediatamente podem-se identificar contradições e inconsistências nas propostas. Tais contradições podem ser de duas naturezas: decorrentes da mesclagem de ideias provenientes das duas agendas, antes citadas, e podem também corresponder à adoção de pontos de vista diferentes, existentes no interior 
de cada uma dessas agendas, ou ainda podem resultar de uma mistura entre eles. Nesse cenário, este artigo se restringe a levantar as convergências existentes entre os dois documentos em termos de temáticas, identificando as duas orientações (tipos ideais) que, em princípio, tais temáticas podem assumir.

O exame do PNE proposto pela CONAE (2010) e do projeto das Diretrizes Nacionais do Ensino Fundamental de 9 (nove) anos encaminhado pelo CNE mostra que, mesmo se tratando de documentos de natureza e fins distintos, há uma grande convergência de ideias entre eles, fruto do percurso de sua construção e da presença de atores que participaram dos dois processos.

Observa-se que os dois documentos enfatizam a ideia de uma educação de qualidade. As Diretrizes baseiam-se em documento da UNESCO para definir o que entende por qualidade, colocando a relevância, pertinência e equidade como seus elementos balizadores. Sendo "qualidade" um termo que abrange diferentes significados, cabe aos futuros estudos na área identificar se há diferença em relação a esse aspecto nos dois documentos e identificar os significados com os quais cada um deles opera.

Da mesma forma, os dois documentos dão destaque à gestão democrática e ao trabalho participativo e coletivo. É preciso distinguir duas matrizes que dão origem a esse tipo de proposta. Uma delas tem origem na ideia de participação como pilar da democracia e é tributária dos movimentos sociais. De forma diferente, há propostas de descentralização e de participação que são derivadas das doutrinas propagadas pelo novo gerencialismo, em uma perspectiva dos ganhos econômicos que podem advir da gestáo descentralizada e do uso da participação como forma de cooptação para ideias já previamente assumidas. Nesse caso, é preciso examinar que tipo de orientação prevalece em cada um desses documentos.

A valorização do magistério também é um ponto comum aos dois documentos e aspecto também defendido pelos documentos da UNESCO. Por um lado, os educadores críticos consideram que o professor, responsável por um trabalho de grande importância e relevância social, deve ter uma boa formação (inicial e contínua), uma carreira bem estruturada e um salário que lhe dê condições de se dedicar a seu trabalho e que, ao mesmo tempo, lhe proporcione uma vida digna. Por outro lado, para uma vertente com posições de viés economicista, desde que as pesquisas 
Diretrizes Curriculares Nacionais para o ensino fundamental de 9 anos...

demonstraram que, depois dos fatores socioeconômicos, o professor é o maior responsável pelo nível de desempenho dos alunos, é preciso que este tenha também uma formação adequada e boa remuneração. Os pontos de vista são semelhantes, mas as razões são diferentes, uma vez que, para a vertente que estou chamando de economicista, tal aspecto é pensado como uma forma do aumento da competitividade do processo de ingresso para essa carreira, garantindo, dessa forma, a seleção dos mais aptos. E claro que os educadores críticos querem também professores competentes, mas tanto sua visão de competência, como sua visão sobre o papel do mercado são bem distintas da compartilhada pelo outro grupo. Interroga-se, então: Que posição predomina nos documentos que estão sendo aqui discutidos?

O aumento da jornada escolar ou a escola em tempo integral é também uma demanda presente nos dois documentos. Entretanto, há distinção na concepção desse novo espaço para os alunos, pela diferença em suas finalidades e, consequentemente, pela diferença no peso das atividades que nele poderão ser desenvolvidas. Para o grupo cujos critérios econômicos são determinantes em suas ações e decisões, a ampliação da jornada escolar propicia oportunidade maior para a aprendizagem dos conhecimentos escolares e para a recuperação dos alunos com problemas de aprendizagem, o que irá melhorar os resultados das escolas nos testes aplicados pelo sistema nacional e/ou local de avaliação. Para aqueles que estou denominando de educadores críticos, a ampliação da jornada escolar também significa maior possibilidade de criação de espaços para estudos, proporcionando aprofundamento dos conhecimentos escolares e contribuindo para a superação de dificuldades de aprendizagem. Porém, mais do que isso, essa ampliação se constitui em um tempo que irá permitir a vivência de outras experiências culturais para a criança e para o jovem. Vivências que ficam limitadas pelo pouco tempo de que dispóem os professores e as escolas para oportunizar às crianças e aos jovens outras experiências indispensáveis ao seu processo de formação, e diferentes daquelas ligadas diretamente à aprendizagem dos conteúdos disciplinares, embora possam a eles se articular. Cabe então perguntar: Quais orientações cada um dos documentos toma? Há contradição nas ideias que apresentam? Há, realmente, convergência de princípios nos argumentos que utilizam?

É preciso destacar que os dois documentos, com um vigor muito maior do que aqueles que os antecedem, dão grande ênfase à diversidade cultural e à diferença. Em ambos é dado destaque a essa questão, com textos específicos sobre educação indígena, educação quilombola e educação 
especial. Também, como nos demais casos, é preciso verificar que posição orienta esses textos, pois, como há muito já é discutido no campo do multiculturalismo, há grande diferença entre as perspectivas existentes nesse terreno. Sacristán (1995) mostra que há muitas ambiguidades no campo do multiculturalismo. Muitas vezes, o diálogo e a interação com o outro têm um objetivo assimilacionista, buscando nessa aproximação uma estratégia para a integração da cultura dos chamados grupos minoritários à cultura dominante. A luta pela eliminação dos preconceitos está, nessa perspectiva, associada a um processo de homogeneização cultural. É por isso que McLaren (2000) prefere o uso do termo "interculturalismo crítico", que supera a orientação centrada na tolerância ao outro, posição esta herdeira do colonialismo. Com base em Candau (2005), pode-se dizer que o interculturalimo crítico reconhece o direito à diferença e luta contra todo tipo de discriminação. Essa posição reconhece também o conflito e não ignora as relaçôes de poder que constituem e são constituídas pelas hierarquias sociais e buscam a solução de problemas, tendo como horizonte a questão da justiça social. Nesse caso, indaga-se sobre que posição orienta cada um dos documentos aqui discutidos. Há predominância, no discurso, de uma visão assimilacionista ou prevalecem as ideias defendidas pelo interculturalismo crítico? Há ambiguidades na argumentação utilizada? Quais são e de que decorrem?

Outras questões que merecem destaque e que são tratadas em ambos os documentos dizem respeito à questão ambiental, à utilização das tecnologias da informação e comunicação (TIC) na educação e à educação de jovens e adultos. Ambos também dão ênfase aos processos de avaliação, mas identifiquei rupturas nesse aspecto em relação aos documentos que os precederam, uma vez que, nos dois documentos em pauta, prepondera a dimensão formativa da avaliação, no sentido de que ela é, principalmente, considerada como instrumento de correção de percursos. Um exame mais minucioso dos dois documentos também irá, sem dúvida, identificar outros pontos comuns. Acrescenta-se a isso que as análises das convergências entre os documentos em pauta também irão mostrar que nos temas tratados há orientações políticas e conceituais de matizes diferentes, ou, ainda, que muitas delas se interpenetram, apresentando-se de forma diversa das polarizações ora construídas, podendo também trazer vestígios de outras tradiçôes.

Como pode ser observado, os temas ora tratados fazem parte de uma agenda que é compartilhada por diferentes órgãos e associações 
que fizeram parte do processo de elaboração e de discussão tanto do PNE, como das Diretrizes para o ensino fundamental. Uma análise mais aprofundada irá mostrar, também, a convergência dessas propostas com aquelas presentes em documentos ou relatórios da UNESCO, como a Declaração Mundial sobre Educação para Todos, aprovada pela Conferência de Jomtiem/Tailândia, em 1990. Cabe também chamar a atenção para o caráter híbrido dos próprios documentos da UNESCO, geralmente analisados como subordinados a uma única perspectiva.

\section{Considerações finais}

A leitura dessa versão das Diretrizes evidencia, sobretudo, o poder dos grupos sociais e políticos, das associações, dos sindicatos e de outras entidades ligadas ao campo educacional, pelo registro claro das vozes desses grupos no interior de todo o documento. Pode-se fazer uma avaliação desse poder e até hierarquizá-lo, em função do número de artigos na resolução, da extensão dos argumentos em torno de determinadas temáticas, que representam interesses mais específicos desses atores sociais. Contudo, percebe-se claramente que tais organizações e entidades não foram ainda capazes de construir uma plataforma comum de interesses, organizando-se para a defesa de um determinado projeto educacional, coerente com suas demandas e expectativas. Laclau e Mouffe (1985) consideram que somente através de uma articulação desse tipo será possível a construção de uma democracia, que eles denominam de "radical", por se constituir em uma estratégia das forças de esquerda, no processo de luta pela superação das injustiças e assimetrias sociais e culturais.

Outro aspecto que deixei para abordar aqui, e que foi por mim observado na proximidade que tive com todo o processo de elaboração e de discussão dessas Diretrizes, diz respeito a uma divergência na posição dos acadêmicos e dos gestores do sistema e das escolas, e mesmo dos professores. É que, enquanto os últimos encaminharam vários pedidos, no sentido da elaboração de "expectativas de aprendizagem", para cada ano do ensino fundamental, os primeiros resistiram e resistem a fazê-lo. Alega-se que elaboraçôes desse tipo desrespeitam as diferenças e as culturas locais ou, ainda, que tais iniciativas são prescritivas, inibem a criatividade e desrespeitam a autonomia docente. Observa-se, assim, que as visões temporais distintas, decorrentes do limite de prazo dos mandatos políticos e das demandas diferenciadas, em virtude do lugar que ocupam no 
sistema educacional, levam-nos a assumir posições também distintas sobre as formas de melhorar a qualidade da educação. Para os gestores, neste caso, é preciso dizer aos professores o que necessitam ensinar em cada ano do ensino fundamental, pois estes se encontram "meio perdidos", precisando de guias seguros. Para os acadêmicos, definidas as orientações gerais, com as finalidades e objetivos do ensino fundamental pelas Diretrizes, cabe aos professores planejarem o ensino, de acordo com a realidade de sua turma, tendo como horizonte essas definições mais amplas que, provavelmente, estarão também presentes em documentos de seus estados e municípios. Este seria um dos caminhos para se garantir a qualidade da educação, por envolver aprendizagens significativas, por estarem enraizadas na realidade local. Essa diferença de ponto de vista levou, na busca pelo consenso, a uma posição em que as diretrizes não apontaram essas "expectativas de aprendizagem", mas foi colocado em seu texto que o MEC terá um prazo de três meses para fazê-lo.

Finalizando, penso ser possível que, ao invés de 50 artigos que integram o Projeto de Resolução das Diretrizes Curriculares Nacionais para o Ensino Fundamental de 9 (nove) anos, encaminhado pelo $\mathrm{CNE}$ ao ministro da Educação, o documento a ser homologado apresente um número menor de artigos, buscando realizar uma síntese do que consta na atual versão. Da mesma forma, haverá diferenças entre a atual proposta do PNE e o texto que será aprovado. Em virtude disso, considero ser importante que os estudos no campo se debrucem não apenas sobre os textos que se tornarão oficiais, mas também sobre os documentos que os antecedem.

Os dois documentos em questão foram produzidos com uma ampla representação dos diferentes grupos que atuam no campo educacional. Identificar e explicar a razão por que determinados aspectos no processo de construção desses textos políticos são excluídos, enquanto outros são inseridos, bem como as diferenças de ênfases que são dadas aos diversos tópicos abordados nas distintas versões de um documento, é um trabalho que torna mais clara a correlação de forças existentes no campo e os interesses em jogo. Esse tipo de análise irá nos tornar conscientes da situação presente e nos fornecerá elementos para uma elaboração de um programa ou de uma agenda de trabalho em prol de futuras conquistas.

Recebido em agosto de 2010 e aprovado em setembro de 2010. 
Diretrizes Curriculares Nacionais para o ensino fundamental de 9 anos...

\section{Notas}

1. Sobre o desempenho da educação básica, conferir resultado do Índice de Desenvolvimento da Educação básica (IDEB, 2009) e também resultados do Sistema de Avaliação da Educação Básica (SAEB) e do Exame de Avaliação do Ensino Médio (ENEM), disponíveis em: $<$ http://educacao.uol.com.br/ultinot/2010/07/05/faca-download-das-planilhas-do-idebdivulgadas-pelo-mec.jhtm>

2. Segundo o site do movimento "Todos pela Educação", este é "financiado exclusivamente pela iniciativa privada, que congrega sociedade civil organizada, educadores e gestores públicos que têm como objetivo contribuir para que o Brasil garanta a todas as crianças e jovens o direito à educação básica de qualidade". Disponível em: <http://www.todospelaeducacao.org.br/ institucional/quem-somos>. Consulta em: 3 set. 2010.

3. Segundo Peters, Marshall e Fitzzimons (2004), o novo gerencialismo tem sido utilizado na educação à medida que esse campo introduz princípios e critérios empresariais, com ênfase na avaliação do desempenho e em medidas baseadas na competividade do mercado.

\section{Referências}

APPLE, M.W. Educating the right way. New York: Routledge-Falmer, 2001.

BALL, S. et al. Reforming education e changing schools: case studies in policy sociology. London: Routledge, 1992.

BALL, S. Educational reform: a critical and post-structural approach. Buckingham: Open University, 1994.

BALL, S. Diretrizes políticas globais e relações políticas locais em educação. Currículo sem Fonteiras, Porto Alegre, v. 1, n. 2, p. 99-114, jul./dez., 2004.

BALL, S. What is policy?: text, trajectories and toolboxes. In: BALL, S. Educational policy and social class: the selected works of Stephen J. Ball. London: Routledge, 2007. p. 43-53.

BALL, S. The education debate. Bristol: The Policy; University of Bristol, 2009.

BRASIL. Ministério da Educação. Conselho Nacional de Educação. Parecer CNE/CEB n. 04/98, de 29 de janeiro de 1998. Institui as diretrizes curriculares nacionais para o Ensino Fundamental. Diário Oficial da União. Brasília, DF, 30 jan. 1998. 
BRASIL. Ministério da Educação. Conselho Nacional de Educação. Parecer CNE/CEB n. 11/2010, de 7 de julho de 2010. Sobre as Diretrizes Curriculares Nacionais para o Ensino Fundamental de 9 anos. Brasília, DF: CNE/CEB, 2010.

CONFERÊNCIA NACIONAL DE EDUCAÇÃO (CONAE), 2010, Brasília, DF. Construindo o Sistema Nacional articulado de Educação: o Plano Nacional de Educação, diretrizes e estratégias; Documento-Referência. Brasília, DF: MEC, 2010. Disponível em: <http://portal.mec.gov.br/ conae/index.php?option=com_content $\&$ view $=$ article $\&$ id $=52$ :referencial $\&$ catid=38: documentos\&Itemid $=59>$.

CANDAU, V.M. Sociedade multicultural e educação: tensões e desafios. In: CANDAU, V.M. (Org.). Cultura(s) e educação: entre o crítico e o pós-crítico. Rio de Janeiro: DP\&A, 2005. p. 13-38.

DALE, R. The State and education policy. Milton Keynes: Open University, 1989.

GOODSON, I.F. Currículo: teoria e história. Petrópolis: Vozes, 1995.

LACLAU, E.; MOUFFE, C. Hegemony e socialist strategy. London: Verso, 1985.

MCLAREN, P. Multiculturalismo revolucionário: pedagogia do dissenso para o novo milênio. Porto Alegre: ARTMED, 2000.

OZGA, J. Investigação sobre politicas educacionais: terreno de contestação. Porto: Porto, 2000.

PETERS, M.; MARSHAL, J.; FITZSIMONS, P. Gerencialismo e política educacional em um contexto global: Foucault, neoliberalismo e a doutrina da autoadministração. In: Burbules, N.; Torres, C.A. (Org.). Globalização e educação: perspectivas críticas. Porto Alegre: ARTMED, 2004. p. 77-90.

SACRISTÁN, G.J. Currículo e diversidade cultural. In: Silva, T.T.; Moreira, A.F. (Org.). Territórios contestados: o currículo e os novos mapas políticos e culturais. Petrópolis: Vozes, 1995. p. 82-113.

TORRES, C.A. The capitalist state and public policy formation. In: BALL, S. The Routledge Reader in sociology of education. London: Routledge-Falmer, 2004. p. 156-195. 
Diretrizes Curriculares Nacionais para o ensino fundamental de 9 anos...

WHITTY, G. Making sense of education policy. London: Paul Chapman, 2002. 